\title{
Weather Monitoring System Using Internet of Things
}

\author{
Md. Majharul Islam* \\ Department of Information \& Communication Engineering, Noakhali Science and Technology University, Bangladesh
}

Submission: September 19, 2019; Published: October 30, 2019

*Corresponding author: Md. Majharul Islam, Department of Information \& Communication Engineering, Noakhali Science and Technology University, Bangladesh

\begin{abstract}
In this research, a foundation is set for an efficient solution for tracking the weather conditions of a specific location and making the information available anywhere in the world. The technological advances behind this is Internet of Things (IoT), which is an efficient and effective solution for linking the things to the web and to connect the entire world of things in a network. Here things could be like electronic gadgets, sensors, and automotive electronic devices. The system functions with tracking and monitoring environmental circumstances such as temperature, relative humidity, light intensity, pressure and quantity of rainfall with sensors and whenever these scores exceed a selected threshold limit for each an e-mail, an SMS alerts the appliance owner to take the required steps.
\end{abstract}

Keywords: Smart Environment; Internet of Things; Weather Monitoring System; Cloud

\section{Introduction}

Present technological innovations focus primarily on managing and tracking various operations. To achieve human needs, these are increasingly emerging. To monitor and evaluate the circumstances in case of exceeding the prescribed level of parameters (e.g. noise, gas and radiation levels), an effective environmental monitoring system is needed. When objects such as environment embedded with sensor devices, microcontroller and multiple software applications become an environment of self-protection and self-monitoring, it is also called a smart environment. In such an environment the alarm or LED alerts automatically occur when some incident happens. The impacts on livestock, crops and humans due to the environmental modifications can be tracked and regulated by a smart monitoring system for the environment. By making the environment interactive with other objectives by using embedded intelligence, this is one of the applications that targets smart environment. Human needs are dependent on the type of information collected by the sensor devices, different kinds of monitoring systems. The two categories to which applications are categorized are based on event detection and spatial process estimation. Initially, sensor systems are implemented in the environment to detect parameters (e.g., temperature, humidity, pressure, LDR, noise, $\mathrm{CO}$ and radiation levels, etc.) while acquiring, computing and controlling information (e.g., noise and gas levels variations in the specified levels).
Sensor devices are positioned at various places to gather information to predict the behavior of a specific area of interest. Here Internet of Things (IoT) is the concept of linking all the sensors to the internet [1]. The primary purpose of this document is to develop and execute an effective monitoring system whereby the necessary parameters are remotely controlled using the internet and the information collected from the sensors are stored in the cloud and analyzed there and then an email, an SMS alerts whenever the threshold limit exceeds [2].

\section{Materials and Methods}

\section{Problem Statement}

The satellite weather reporting system provides the current condition that does not give the exact location condition. The drawbacks are in conventional approach where the devices are costly and have no visualization of information. There is no such automatic tool to offer the alert signal in case of any abnormalities, so it is difficult to regulate this abnormality.

\section{Proposed Model}

Weather conditions are tracked in the home's external environment or any buildings and information are transferred to the cloud server. The benefits will be that this system will manually transmit the real-time environment information. It is possible to view the information in any part of the world. This application is 
to monitor and update the condition of the surroundings regularly. Conditions of the environment can be tracked by gathering the data from the sensors and deposited in the cloud and analyzed there and then an email, an SMS alerts if the situation of the environment becomes abnormal.

\section{Environment Monitoring System}

An IOT application is used to monitor the environment that helps monitor the environmental condition of any local area or a surrounding area, and with the help of the internet everyone can view the condition. This application is more efficient, quicker in offering conditions for the environment [3]. It enables people or government to take remedial action if the environmental condition becomes abnormal. Environmental condition monitoring system offers a technique for verifying the condition and changes occurs over the surrounding. In this system we use Arduino, sound sensor, gas sensor, temperature sensor, moisture sensor, pressure sensor, IOT module. The humidity and temperature sensor will track climate change and provide information. It is helpful for agriculture [4]. To monitor pollution over the atmosphere, the gas and sound sensor are used. Currently, pollution from air and noise makes the environment more susceptible. Using this module, we can identify the polluted area and expressly create people's consciousness for living in the pollution. Changes in the climate system cannot be accurately defined and sometimes accidentally defined, but with the help of an IOT module we can characterize more approximate changes in an environment and update them in the cloud. This system uses many modules as follows:

Sensor Module: The sensor network is linked to a hefty amount of small sensor nodes that can be used as an effective tool for collecting information for different applications under different situations [5,6]. Different sensors are integrated into this study that has its distinctive way of collecting information from the surroundings. An integrated circuit sensor (LM35) used to evaluate temperature with an electrical output proportional to the temperature $\left(\mathrm{in}{ }^{\circ} \mathrm{C}\right)$. If the temperature goes up, the fan is going on and vice versa. The factor of scale is $.01 \mathrm{~V} /{ }^{\circ} \mathrm{C}$. The LM35 requires no external calibration or trimming and retains $\mathrm{a}+/-0.4^{\circ} \mathrm{C}$ accuracy at room temperature and $+/-0.8^{\circ} \mathrm{C}$ over $0{ }^{\circ} \mathrm{C}$ to $+100{ }^{\circ} \mathrm{C}$ range.

System utilizes moisture sensors DHT11. It provides outstanding quality, quick response, capacity to prevent interference, and cost-effectiveness. On the calibration of humidity, this sensor is highly precise.

MQ-6 gas sensor's sensitive material is $\mathrm{SnO}$, which has lower conductivity in clean air. The MQ-6 gas sensor is highly sensitive to Propane, Butane and LPG, as well as natural gas response. The Sensor could be used to detect various fuel gases, particularly methane; it is appropriate for separate applications at a low price.

The sound sensor module offers a straight-forward sound monitoring technique and is generally used for sound power de- tection. This module can be used for apps for safety and tracking. Its precision for comfort of use can be readily adapted.

The BMP180 is an I2C standard device and a pressure sensor. It's a 4-pin tool, i.e., SDA, SCL, VIN, GND. The connection between Vin and GND is 3.3V and GND. SDA connects to the nodemcu D2 pin and SCL connects to the nodemcu D3 pin.

Power Module: The Power for the system can be provided via the adapter or the USB. Use the USB cable or an external power supply to power the Arduino board. Source of power can be selected automatically.

Controller Module: This implementation is controlled by Arduino UNO. The Arduino board transforms to digital data the analog data produced by the sensor. Arduino is generated to monitor or comprehend the environment or surroundings by receiving feedback from a variety of sensors and can impact its atmosphere by controlling lights, engines, and other actuators. The board's microcontroller is programmed using the Arduino programming language and Arduino development environment. Arduino projects can be separated or when operating on a desktop they can interact with software.

IoT Module: The IoT board is intended to satisfy a range of online application demands with different benefits that allow the embedded system designer to readily, rapidly and seamlessly add internet connectivity to their applications. The module's UART update feature and webpage management make them excellent for online wireless applications like environmental sensors and information from moveable battery-operated wireless sensor network devices. Lumisense IoT board is designed with SIM900 GPRS modem for active internet connection so that it is equipped with a controller for processing all UART data based on GPRS online data.

Light Dependent Resistor (LDR): An LDR is a light-controlled variable resistor. The LDR's strength is reduced by the increasing light intensity falling on it. It has an analog output that is an input to the nodemcu's A0 pin.

Raindrop Module: It is used for rain detection. It can also be used to measure rain intensity. It has both digital and analog output. This module analyses the moisture by means of analog output pin and gives a digital output when the moisture limit exceeds too much. The more water or less resistance implies the reduced voltage of the output. Whereas, the less water implies higher resistance, i.e, high output voltage on the analog pin. For instance, a totally dry board will result in five volts of module output. The module's analog output is linked to the nodemcu's A0 pin.

Working of the Analog Pin (A0): The Nodemcu board has only 1 analog pin, but two analog output devices, viz, LDR and Raindrop module, are multiplexed to the A0 using two diodes in this project. The circuit of multiplexing is shown in Figure 1 below. Here the Raindrop Vcc sensor is connected to the nodemcu D7 and the LDR input is connected to the nodemcu D8. When D7 is high, D8 is low, making LDR off and module raindrop on. Thus, 
the raindrop sensor output reaches the nodemcu A0 through the diode. Similarly, when D8 is high and D7 is low, the LDR is on and the raindrop module is off creating a route for the LDR output to achieve the nodemcu A0 through the second diode.

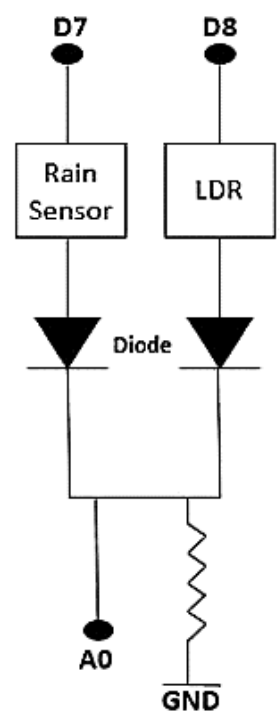

Figure 1: Multiplexing circuit.

\section{Execution}

Arduino is driven by a USB cable and the four sensors are linked to the Arduino board and the information collected from the sensors is stored in the cloud and analyzed there and then an email, an SMS alerts whenever the threshold limit exceeds. The IoT module is also linked to the Arduino board to receive feedback from the sensors and is driven by the adapter. The USB cable gives power to the Arduino board and then transfers information from Arduino board to the computer.

\section{Results}

Once the sensor measures are downloaded to the cloud, the values are evaluated and then the threshold limit exceeds an e-mail, an SMS and a tweeter post are posted. Some findings of the study are as follows Figures 2 \& 3.

\section{majharulislam.ice@gmail.com}

to me -

\section{Humidity at device 5CCF7F1E17DF is $27 \%$ !}

\section{majharulislam.ice@gmail.com}

to me -

\section{Temperature at device 5CCF7F1E17DF is 29 degrees!}

Figure 2: Email received. 


\section{Sent from your Twilio trial} account - Temperature at device 5CCF7F1E17DF is 29 degrees!

airtel -7 Nov

\section{Sent from your Twilio trial account -} Humidity at device 5CCF7F1E17DF is $28 \%$ !

Figure 3: Message received.

Algorithm 1: Analog Pin Multiplexing

Input: LDR D8, raindrop D7;

Output: Analog pin A0

$\operatorname{loop}\{$

if $($ digitalRead(D7) $==$ HIGH $)$

\{

$\mathrm{A} 0=$ raindrop sensor value;

digitalWrite(D7, LOW);

\}

else if $($ digitalRead(D8) $==$ HIGH $)$

\{

$\mathrm{A} 0=\mathrm{LDR}$ value;

digitalWrite (D8, LOW);

\}

\}

Algorithm 2: E-mail, SMS

Input: temp, humidity, press, LDR, rain;

Output: email, sms

$\operatorname{loop}\{$

temp=temperature value measured;

humidity=humidity value measured;

press=pressure value measured;

LDR=light intensity measured;

rain=rain value measured;

if (temp \&\& humidity \&\& press \&\& LDR \&\& rain)

\{

publish all the measured value to the cloud bluemix;

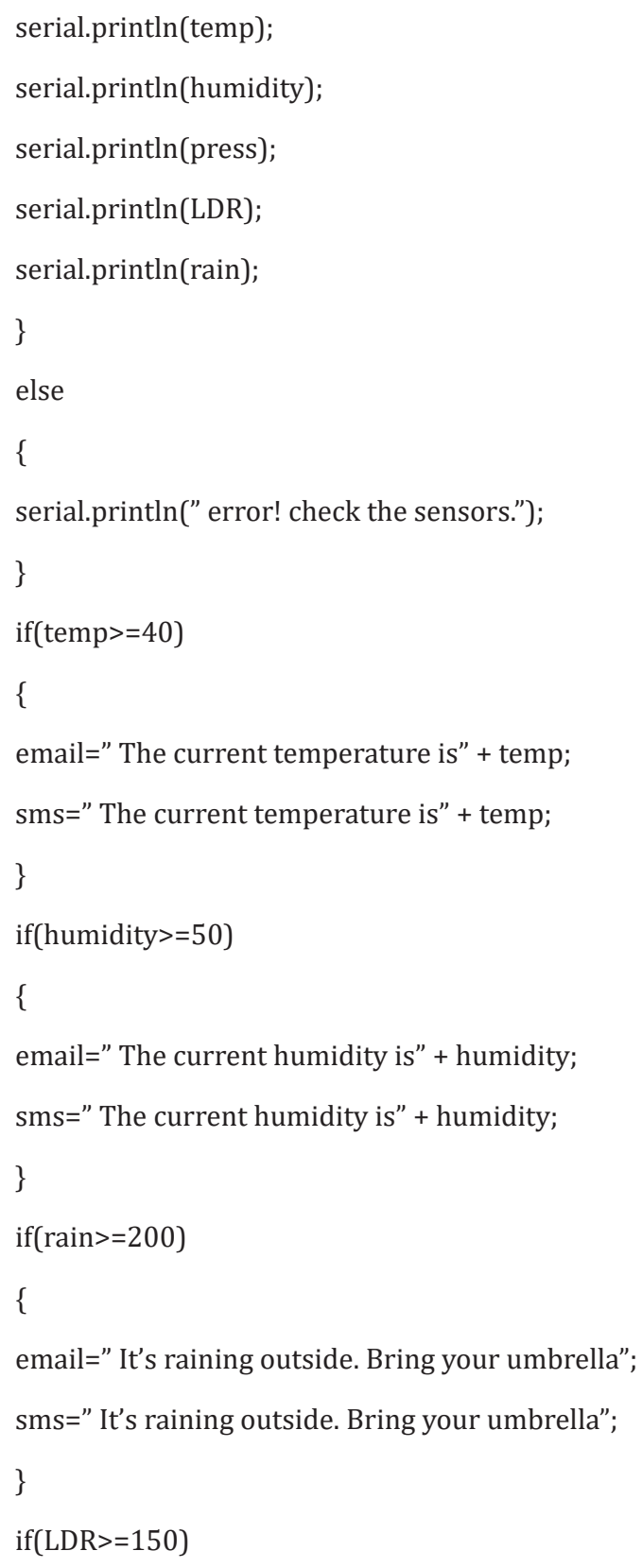


post only once in a day

\{

email=" Good Morning";

sms=" Good Morning";

\}

\}

\}

\section{Conclusion}

This System monitors the changes happening over the environment and provides enough ways for the users to access the information from anywhere through cloud. The temperature and humidity sensor will monitor and gives the details about the changes happening over the climate. The gas and sound sensor are used for monitoring the pollution over environment. The Monitored condition will be updated in the cloud.

\section{References}

1. Rao BS, Rao KS, Ome N (2016) Internet of Things (IOT) based weather monitoring system. International Journal of Advanced Research in Computer and Communication Engineering Sep 5(9): 312-319.

2. Gangopadhyay S, Mondal MK (2016) A wireless framework for environmental monitoring and instant response alert. In International Conference on Microelectronics, Computing and Communications (MicroCom) Jan 23 IEEE. p. 1-6.

3. Bulusu N, Estrin D, Girod L, Heidemann J (2001) Scalable coordination for wireless sensor networks: self-configuring localization systems. In International Symposium on Communication Theory and Applications (ISCTA 2001), Ambleside, UK.

4. Riquelme JL, Soto F, Suardíaz J, Sánchez P, Iborra A, et al. (2009) Wireless sensor networks for precision horticulture in Southern Spain. Computers and electronics in agriculture. 68(1): 25-35.

5. Kumar D, Aseri TC, Patel RB (2010) EECHDA: Energy Efficient Clustering Hierarchy and Data Accumulation for Sensor Networks. BIJIT 2(1): 150-157.

6. Cerpa A, Estrin D (2004) ASCENT: Adaptive self-configuring sensor networks topologies. IEEE transactions on mobile computing 3(3): $272-285$.

\section{Your next submission with Juniper Publishers will reach you the below assets}

- Quality Editorial service

- Swift Peer Review

- Reprints availability

- E-prints Service

- Manuscript Podcast for convenient understanding

- Global attainment for your research

- Manuscript accessibility in different formats

( Pdf, E-pub, Full Text, Audio)

- Unceasing customer service

Track the below URL for one-step submission https://juniperpublishers.com/online-submission.php 